\title{
RESUMO
}

\section{RACISMO E VIOLÊNCIA OBSTÉTRICA: A PROTEÇ̃̃O INTERSECCIONAL DA MULHER}

RACISM AND OBSTETRIC VIOLENCE: WOMEN'S INTERSECTIONAL PROTECTION

\author{
RACISMO Y VIOLENCIA OBSTÉTRICA: \\ PROTECCIÓN INTERSECCIONAL DE LAS MUJERES
}

0 número de mulheres vítimas de violência obstétrica cresce de forma exponencial diariamente; estima-se que $62,8 \%$ das mortes são de mulheres negras, de modo que revela o racismo institucional nos hospitais. Contudo, o assunto é negligenciado e sua prática não reflete sanções relevantes, mas tão somente indenizações por dano moral. Dessa forma, o presente trabalho científico tem como objetivo principal apresentar, a partir de uma pesquisa doutrinária e legislativa, a viabilização da discussão a partir de uma visão interseccional e defensora dos direitos humanos, além de apresentar argumentos favoráveis à criminalização dessa conduta.

\section{PALAVRAS-CHAVE}

Violência obstétrica. Racismo institucional. Direitos Humanos. Direitos fundamentais. Criminalização. 


\section{ABSTRACT}

The number of women victims of obstetric violence grows exponentially daily; it is estimated that $62,8 \%$ of deaths are of black women, thus revealing institutional racism in hospitals. However, the matter is neglected and its practice does not reflect relevant sanctions, but only damages for moral damage. Thus, the present scientific work has as main objective to present, from a doctrinal and legislative research, the feasibility of the discussion from an intersectional and defender of human rights view, in addition to presenting arguments favorable to the criminalization of this conduct.

\section{KEYWORDS}

Obstetric violence. Institutional racism. Human rights. Fundamental rights. Criminalization.

\section{RESUMEN}

El número de mujeres víctimas de violencia obstétrica crece exponencialmente a diario; se estima que el $62,8 \%$ de las muertes son de mujeres negras, lo que revela el racismo institucional en los hospitales. Sin embargo, el asunto se descuida y su práctica no refleja sanciones relevantes, sino únicamente indemnizaciones por daño moral. Así, el presente trabajo científico tiene como objetivo principal presentar, desde una investigación doctrinal y legislativa, la viabilidad de la discusión desde una mirada interseccional y defensora de los derechos humanos, además de presentar argumentos favorables a la criminalización de esta conducta.

\section{PALABRAS CLAVE}

Violencia obstétrica. Racismo institucional. Derechos humanos. Derechos fundamentales. Criminalización. 


\section{INTRODUÇ̧̃̃o}

O presente trabalho científico inspirou-se no fato de que segundo os dados do Ministério da Saúde em 2018, 65,9\% das mulheres vítimas da violência obstétrica são negras, o que demonstra não só o sexismo, mas também - e principalmente - o racismo impregnado nas instituições. De forma paradoxal, embora o número de mulheres atingidas seja alarmante, a sociedade mantém mascarada essa violência, tendo em vista que no debate ínfimo que existe, o corpo negro, geralmente, não é o centro da discussão, apesar de ser o mais violado.

De forma lógica, percebe-se que o motivo da negligência acerca da violência obstétrica se dá pela ausência de informações suficientes, já que, muitas vezes, essas práticas são encobertas e, assim, dadas como procedimentos necessários ou, até mesmo, como uma prática desejada pela paciente. Analogamente, não se faz distinta a discussão ao tratar de mulheres negras, faz-se pior, visto que se banaliza ainda mais o debate acerca do motivo pelo qual essas mulheres são os maiores índices de mortalidade materna, o que provoca violação de direitos humanos e fundamentais, como o direito reprodutivo.

Isso se dá porque os indivíduos os quais não vivenciam essa realidade - a qual o corpo negro é alvo constante de abuso por parte do Estado - não possuem essa visão no seu lugar de fala, conforme aborda Djamila Ribeiro em sua obra O que é lugar de fala? Nesse sentido, apesar de poderem debater, essas pessoas nunca saberão a dor vivenciada e embora haja muitos indivíduos os quais busquem a desconstrução diária, é preciso saber que aqueles oriundos das classes dominantes são os abusadores e ao se omitirem em uma situação de racismo, corroboram com a estrutura opressora vigente, não bastando, assim, não ser o racista, mas devendo lutar contra este preconceito constantemente, assim como aborda Silvio de Almeida em seu livro O que é racismo estrutural?

Desse modo, o presente trabalho busca tratar do racismo institucional na saúde obstétrica a partir de um viés interseccional-feminista para que, assim, desconstrua-se a visão binária que a sociedade possui acerca das opressões vivenciadas, a fim de que a violência obstétrica passe a ser discutida em todos os âmbitos e, sobretudo, no contexto do racismo institucional.

\section{VIOLÊNCIA OBSTÉTRICA EM MULHERES NEGRAS}

A gravidez é um momento de extrema felicidade na vida da mulher, mas também de muitas incertezas, dúvidas e medos, cuja história sofreu diversas mudanças ao longo do tempo, eis que até o parto era domiciliar até a primeira metade do século XX e, posteriormente, com a evolução da medicina, tornou-se hospitalar, momento em que começaram a surgir casos de violência obstétrica (STURZA; NIELSSON; ANDRADE, 2020, p. 391).

A expressão violência obstétrica é utilizada para descrever um conjunto de variadas formas de violência durante o cuidado do profissional obstetra, seja ela física, psicológica ou verbal, além, tam- 
bém, de incluir procedimentos danosos e inúteis, a exemplo da episiotomias, tricotomia, cesárea, ausência de acompanhante (TESSER, 2015, p. 2). A violência obstétrica pode ser praticada durante toda a gravidez, porém é no momento do parto que ocorre a maioria dos casos de violação dos direitos da mulher, é dizer, de abusos, maus-tratos e agressões de todas as espécies, porque é nessa fase que ela, a mulher, encontra-se física e mental mais vulnerável (STURZA; NIELSSON; ANDRADE, 2020, p. 392).

Reconhecida pela Organização Mundial da Saúde (OMS) em 2014 como questão de saúde pública, essa violação revela uma objetificação da mulher e, consequentemente, a retirada do protagonismo feminino, o que caracteriza desrespeito pela dignidade da pessoa humana, constituindo, assim, mais uma violência de gênero. Apesar de parecer um problema esporádico, de acordo com a Pesquisa da Fundação Perseu Abramo e Serviço Social do Comércio (SESC), em 2010, uma entre quatro mulheres já sofreu violência obstétrica. 0 referido dado denuncia a violência mascarada na sociedade, o que contribui para sua reincidência rotineira, uma vez que uma parcela ínfima percebe sua ocorrência. Isso se dá porque os tratamentos realizados aparentam ter a finalidade de facilitar o parto para a mulher, contudo, o que acontece, na realidade, é a intenção de agilizar as etapas, inclusive induzindo o nascimento, não importando o quão intervencionista isso possa ser (REDE PARTO..., 2012, p. 11-20).

A episiotomia, por exemplo, é uma prática a qual há um corte na região do períneo utilizada com a justificativa de facilitação do parto, de redução dos riscos de traumas e de manutenção da integridade genital da parturiente. Entretanto, já foi comprovado que essas constatações não passam de desculpas para sua ocorrência, visto que, em 1996, a OMS assegurou o erro da sua reiteração, pois não é profilática com relação aos traumas, mas sim geradora de dor e de desconforto nas pacientes, além de potencializar futuras complicações.

Apesar de já verificada a sua inutilidade, a pesquisa Nascer no Brasil (2014), revelou que isso ocorre em $53,5 \%$ das mulheres. Esses dados demonstram a falta de conhecimento da população acerca dos instrumentos de violação aos direitos humanos, visto que embora sofra no momento, acredita ser o correto para proteção do feto, inclusive - apesar de não haver dados oficiais do Sistema único de Saúde (SUS) - este procedimento está incluído no pacote de assistência ao parto como parte do atendimento padrão (DINIZ; CHACHAM, 2006, p. 81-85).

De acordo com a pesquisa de 2016 da OMS, as cesáreas correspondem a 55\% dos partos realizados no Brasil. Tal informação revela que o parto vaginal tem tido aplicação cada vez mais subsidiária, diferente do que deveria ocorrer. Essa preferência pela tomotocia se dá por escolha dos médicos, pois enxergam o medo da dor como uma justificativa e identificam riscos imaginários, ou por preferência das mães, o que está intrinsicamente ligado à desumanização do parto vaginal, uma vez que as mutheres têm optado pela cirurgia para prevenir sequelas físicas e, sobretudo, psicológicas.

Ou seja, embora, às vezes, seja escolha própria, ainda assim constitui uma violência institucional, pois se sente sem saída para preservar sua dignidade devido à negligência das instituições que deveriam preservar, respeitar e garantir seus direitos. A reiteração dessa prática contribui para a prolongação da peregrinação das mães nas maternidades devido ao tempo de recuperação ser mais longo. Assim, demora mais tempo para haver a desocupação dos leitos nas instituições. Conforme observado por Simone G. Diniz (2009, p. 320): 
No Brasil, além do parto espontâneo ser percebido pelos profissionais como mais arriscado para o bebê, também é tido como mais arriscado para a própria mãe, sendo associado a danos sexuais irreversíveis. Os profissionais praticam intervenções sobre a vagina, como a episiotomia (que é uma laceração de $2^{\circ} \mathrm{grau}$, no mínimo) e os fórceps, que aumentam os riscos de danos genitais graves, e quando estes danos ocorrem, responsabilizam o parto em si pelos danos. Desta forma, o dano iatrogênico é invisibilizado e reescrito como um dano "natural" do parto, associado ao processo fisiológico e não às intervenções.

Apesar de a violência obstétrica ser uma agressão de gênero, ela é, sobretudo, uma violência interseccional, uma vez que $60 \%$ da mortalidade materna no país tem como vítima as mulheres negras e somente $27 \%$ delas possuem acompanhamento durante o parto, enquanto nas mulheres brancas 0 percentual é de 46,2\%, como evidencia a campanha realizada pelo Ministério da saúde denominada de SUS sem racismo em 2014. Outra pesquisa realizada na monografia Raça e violência obstétrica no Brasil (LIMA, 2016, p. 9) possui estatísticas similares, nas quais mulheres negras e pardas são as que mais passam por um processo de desumanização.

\subsection{CONTEXTO HISTÓRICO DO PRECONCEITO}

A escravidão, em todo o mundo, foi um período de extrema violação aos Direitos Humanos, no qual os negros eram tratados como mercadorias a serem comercializadas ou como objetos a serem dados para relações sexuais, tendo como exemplo os diversos abusos praticados pelos senhores em negras escravizadas (DAVIS, 2016, p. 25).

Essa coisificação e desumanização não ocorreu diferente no Brasil, muito pelo contrário, sendo o último a abolir a escravidão e o país que mais recebeu africanos (GOMES; SCHAWCZ, 2018, p. 18). Apesar de ter sido abolida em 1888 pela Lei Áurea, após muita mobilização e resistência, a sua eficácia não compreendeu o fim da marginalização da população negra, uma vez que o espírito da lei abolicionista não era de garantir a dignidade dos indivíduos ao retirar eles da condição de escravo, mas sim de promover o desenvolvimento do país para gerar mais lucro, em virtude do Brasil ser o único que ainda adotava o regime escravocrata enquanto todos os outros superaram essa posição a partir do mercantilismo e imperialismo (COSTA, 1998, p. 432).

Com o fim da escravidão, o Brasil encontrava-se com uma população predominantemente negra e como forma de controle social surge o branqueamento com a inserção de imigrantes - fortalecido pela Teoria Darwinista que estava presente nesse período (SCHAWCZ, 2018, p. 38) - europeus tornando-se inclusive política pública ao proibir a imigração de negros. Tal realidade contribui para o cenário atual de desigualdade social, o que para Nogueira (2017) significa a transformação do racismo em uma prática social dominante na qual liga ideologicamente os brancos, mantendo seus privilégios, enquanto é negada a cidadania aos negros e negras.

Nesse contexto, as dificuldades que as mulheres negras encontram são muito maiores do que as das mulheres brancas. A escritora Djamila Ribeiro (2019, p. 34-39) retrata como essa discriminação é 
vista pelas escritoras Gradha Kilomba e Simone de Beauvoir, uma vez que enquanto Simone de Beavouir classifica a mulher branca como Outro devido à submissão ao homem, tendo assim um espaço oscilante na sociedade, já Gradha Kilomba classifica a mulher negra como a intersecção de Outro do Outro, pois sua luta não é só contra a dominação dos homens, mas também contra a dominação dos brancos, não ocupando espaço nenhum na sociedade.

Essa classificação é fruto da interseccionalidade, isto é, um conjunto de opressões aos indivíduos, no qual impossibilita, ainda mais, uma posição favorável na sociedade, já que há uma combinação das mais diversas violências originadas, sobretudo, pelo pensamento colonial. Nesse sentido, afirma Kimberlé Crenshaw (2002, p. 177):

[...] uma conceituação do problema que busca capturar as consequências estruturais e dinâmicas da interação entre dois ou mais eixos da subordinação. Ela trata especificamente da forma pela qual o racismo, o patriarcalismo, a opressão de classe e outros sistemas discriminatórios criam desigualdades básicas que estruturam as posições relativas de mulheres, raças, etnias, classes e outras. Além disso, a interseccionalidade trata da forma como ações e políticas específicas geram opressões que fluem ao longo de tais eixos, constituindo aspectos dinâmicos ou ativos do desempoderamento.

Dessa forma, as mulheres negras têm, constantemente, seus direitos humanos e fundamentais atacados, pois possuem outros eixos de poder no qual são subordinadas, facilitando essa incidência. Com isso, comprova-se a necessidade em se observar as violações sob uma ótica interseccional, sendo o único meio de desenvolver intervenções e promover mecanismos de proteção verdadeiramente eficazes (CRENSHAW, 2002, p. 174-178).

Essa interseccionalidade funciona, basicamente, como uma hierarquia social na qual o homem branco estaria no topo, a mulher branca logo abaixo, seguida do homem negro, até, por fim, a mulher negra (HOOKS, 2018, p. 40). Todavia, a constante batalha contra o sistema dominante é um desafio, pois muitos acreditam na existência da democracia racial simplesmente porque o racismo, na maioria das vezes, não é explícito.

É importante perceber que, atualmente, o preconceito contra os negros, em sua maioria, acontece de forma implícita, configurando o racismo estrutural. 0 que significa olhar as práticas racistas não só sob uma ótica explícita, mas também como uma visão presente, até mesmo, no inconsciente coletivo, pois esse preconceito constitui as relações sociais na sua normalidade, isto é, a branquitude torna-se o padrão, reverberando a relação de poder em todos os setores da comunidade social, o que gera a discriminação desses grupos sociais de forma sistemática (ALMEIDA, 2017, p. 34). Assim, apesar de o racismo poder não se manifestar de forma individual em todas as pessoas, constitui-se integrante das relações sociais, cabendo à população adotar práticas antirracistas, constantemente, visto que o silêncio mantém a supremacia, veja-se,

Consciente de que o racismo é parte da estrutura social e, por isso, não necessita de intenção para se manifestar, por mais que calar-se diante do racismo não faça do indivíduo

Interfaces Científicas • Aracaju • V.8 • N.3 • p. 37 - 54 • $2021 \cdot$ Fluxo Contínuo 
moral e/ou juridicamente culpado ou responsável, certamente o silêncio o torna ética e politicamente responsável pela manutenção do racismo. A mudança da sociedade não se faz apenas com denúncias ou com o repúdio moral do racismo: depende, antes de tudo, da tomada de posturas e da adoção de práticas antirracistas (ALMEIDA, 2017, p. 35).

Ademais, sob essa perspectiva o racismo pode ser dividido em processo político e processo histórico. Em primeiro plano, essa prática faz parte de um processo político porque os grupos majoritários impõem sobre aqueles desfavorecidos diversas desvantagens sociais, podendo ser feita de forma explicita ou sutilmente. Em segundo plano, é um processo histórico, visto que a estrutura do racismo está ligada, diretamente, à formação histórico-cultural (ALMEIDA, 2017, p. 35-37).

Nesse sentido, é de extremo valor o reconhecimento dessa hostilidade para enfrentá-la e, assim, obter uma sociedade justa e igualitária nos moldes do Art. 3 da Constituição Federal do Brasil de maneira que alcance a decolonialidade.

\subsection{RACISMO INSTITUCIONAL}

As instituições são instrumentos de controle social criadas pela sociedade dentro da sua própria estrutura (MARQUES, 2017, p. 212), os quais visam padronizar comportamentos, ou seja, têm como objetivo manter a supremacia de determinados grupos raciais (ALMEIDA, 2017, p. 31) já que são legitimadas pelo Estado (LOPEZ, 2012, p. 124), visto que, como disserta Marques (2017), o ordenamento jurídico é o principal arranjo institucional na sociedade.

Contudo, há alguns autores, como o membro da Câmara Técnica de Ginecologia e Obstetrícia da SOGIMIG Roberto Magliano de Morais $^{3}$, com a finalidade de deslegitimar o termo ao apresentar a violência nas maternidades como uma falácia e a peregrinação como fruto da precariedade do sistema de saúde comprovada pela insuficiência de equipamentos, leitos ou medicações em conjunto com a sobrecarga dos atendimentos e a baixa remuneração desses profissionais. Entretanto, a desassistência em mulher negra é, incontestavelmente, maior que em uma mulher branca, conforme aponta o Relatório Anual Socioeconômico da Mulher (RASEAM), de 2017.

Esse cenário denuncia não só o sucateamento da área da saúde, mas também a seletividade no atendimento e na inequidade na promoção da dignidade humana originada da discriminação racial construída por meio do regime escravocrata e permeada até os dias de hoje por meio das instituições excludentes.

Diante disso, a perduração dessa disparidade pode ser comprovada no que tange ao acesso à saúde, visto que $67 \%$ dos usuários dos hospitais da rede pública são negros (MINISTÉRIO DA SAÚDE, 2017). Em contrapartida, como já constatado no presente artigo, as mulheres negras são as mais violadas quando deveriam ser assistidas pelos profissionais. Sob a ótica de Leal, Gama e Cunha (2005), a exclusão é fruto, também, da desigualdade racial no acesso à educação, gerando, consequentemente, dificuldade na inserção no mercado de trabalho e na acessibilidade de informação. Tal cenário faz parte do inconsciente coletivo de inferioridade da população negra e, até mesmo, da sua animalização por considerar esses indivíduos como selvagens.

Enquanto a branquitude feminina enfrenta o mito da fragilidade feminina que serviu de pretexto 
para o paternalismo e proteção dos homens sobre elas, as mulheres não brancas constituíam o "Mito da mulher negra", pois elas sempre foram consideradas fortes e mais capazes de suportar a dor do que as outras (LÓPEZ, 2012, p. 131). Esses pensamentos são ratificados pelo ditado do período colonial "Branca para casar, mulata para f..., negra para trabalhar" (FREYRE, 2003, p. 36). Tal imaginário implica na ausência de determinados procedimentos a fim de amenizar a dor no momento do parto, a exemplo da menor aplicação de anestesia local nessas parturientes em comparação com as outras, como constatado por Leal e outros autores (2017, p. 5).

Assim como houve o branqueamento no período posterior à escravidão, a tentativa de controle social mais recente é a chamada esterilização cirúrgica utilizada de forma indiscriminada e destinada a mulheres negras e pobres, principalmente (MONTEIRO et al., 2012, p. 134-146). Essas cirurgias eram oferecidas de forma irresponsável, acompanhada de informações falsas a respeito da laqueadura, como a falácia sobre a possibilidade de reversão.

Não obstante, essa "epidemia" dos anos 1980 foi considerada, muitas vezes, requisito para a possibilidade de ingresso no mercado de trabalho, visto que muitos empregadores exigiam o atestado de esterilização. 0 mesmo medo que fomentou o branqueamento é o medo que impera essa técnica recente: inversão dos dominantes e dominados. Esse temor é visto na fala do antigo deputado Luiz Carlos Santos, na qual demonstra a negação à participação política:

[...] Assim temos, 65 milhões de brancos, 45 milhões de pardos e um milhão de negros. A manter essa tendência no ano 2000 a população parda e negra será de ordem de $60 \%$, portanto muito superior a branca, e eleitoralmente poderá mandar na política e dominar postos chaves. A não ser que façamos como em Washington, capital dos Estados Unidos, que devido ao fato da população negra ser da ordem de 63\% não há eleições ${ }^{4}$ (SANTOS, 1982 apud MONTEIRO, 2012, p. 137-138).

Nesse contexto, o feminismo negro denuncia essas tentativas de genocídio ao verificar a existência do referido documento. Diante disso, uma Comissão Parlamentar Mista de Inquérito (CPMI) do Congresso Nacional investigou, em 1993, esses casos e passou a regulamentar a esterilização cirúrgica.

Diante dos fatos expostos, é nítido que a presença do movimento negro feminista contribui para a luta contra a hegemonia e, consequentemente, para a efetivação dos direitos humanos e o fim do genocídio. Desse modo, a análise do seu surgimento e sua relação com os direitos positivados é de suma importância.

\section{ORIGEM E IMPORTÂNCIA DO FEMINISMO NEGRO}

Diante de um cenário estruturalmente sexista no século XIX, o feminismo surge como um movimento para sanar a exploração sexista e a opressão (HOOKS, 2015, p. 18). Entretanto, houve divisões de acordo com os direitos em que se buscava alcançar, sendo essas repartições denominadas

4 Pronunciamento do deputado Luiz Carlos Santos em São Paulo, em 5 de agosto de 1982 a respeito do documento “O censo de 1980 ”. 
de ondas do feminismo. A primeira onda teve início no século XIX e suas pautas giravam em torno do direito ao voto e à vida pública. A seguinte, na década de 1970, teve como objetivo a luta pela valorização do trabalho, obtenção de direitos relacionados ao prazer feminino e fim da violência sexual. Já a terceira onda, em 1990, surge como uma correção a anterior ao visibilizar as diversas identidades femininas (HOOKS, 2015, p. 40-55).

Essa falha na qual a última onda almeja corrigir é a perpetuação do movimento pela ótica universal. 0 feminismo que estava em ascensão acentuava a exclusão de diversas mulheres, como as negras. Isso se dá porque era engajado, em sua maioria, por mulheres brancas com uma classe econômica favorável que se conformaram em um alcance apenas reformista e não revolucionário, além de que os direitos buscados pelas não negras são distintos (HOOKS, 2015, p. 18). Primeiramente, é válido observar que pensamento reformista visa a igualdade de gênero, enquanto o revolucionário tem como meta a desinstitucionalização do patriarcalismo.

Contudo, a partir do momento que o reformista serviu como alcance para mobilidade social, a maioria das mulheres - brancas - abandonaram a ideia de sanar o sexismo e contentaram-se viver em uma sociedade machista (HOOKS, 2015, p. 20-52). Ademais, como as mulheres negras presenciam um cenário de violência interseccional, elas, muitas vezes, não se identificam com o feminismo hegemônico, até porque este significava o aumento do poder branco (HOOKS, 2015, p. 56).

Nesse sentido, o feminismo negro ganha incidência nos Estados Unidos em 1960 e 1980 a partir da Fundação National Black Feministe literaturas feministas. Enquanto no Brasil ganha forças a partir do $3^{\circ}$ Encontro Feminista Latino-Americano em Bertioga, 1985. Diante desse cenário, o feminismo contra hegemônico foi sendo consolidado a partir do surgimento de Organizações Não Governamentais (ONGS) destinadas a tratar de assuntos como violência doméstica, discriminação racial e saúde reprodutiva (MONTEIRO et al., 2012, p. 136).

Assim sendo, como disserta HookS (2015), o feminismo não branco é extremamente importante para retirar as mulheres negras de condições subalternas, uma vez que o movimento europeizado trata essa luta apenas como um modelo binário (feminismo x masculino), porém as identidades das mulheres não se reduzem somente ao gênero, mas sim a diversos fatores, a exemplo de orientação sexual, religião e etnia. Desse modo, universalizar o confronto é colaborar para a manutenção da marginalização desses indivíduos, pois há situações nas quais as mulheres brancas não sofrem com mais incidência devido à sua cor, como as práticas racistas nas instituições.

Em 1980, a pauta feminista ganhou incidência para a questão dos direitos reprodutivos, pois essas mulheres reivindicavam para o Poder Público a necessidade não só de proteção a esses direitos, mas também de promoção e respeito. Diante desses movimentos reivindicatórios, em 1983 foi criado o Programa de Assistência Integral à Saúde da Mulher (PAISM) o qual fomentou ao poder constituinte a necessidade de se incluir os direitos reprodutivos na Constituição Federal de 1988. Além de permitir, também, a inclusão dessa pauta na Conferência internacional sobre população e desenvolvimento de Cairo em 1994 (CIPD), e na IV Conferência Mundial sobre a Mulher realizada em Pequim no ano posterior (MONTEIRO et al., 2012, p. 140-144). 


\subsection{DIREITO REPRODUTIVO COMO DIREITO HUMANO E FUNDAMENTAL}

Em primeiro plano é importante destacar que a positivação dos Direitos Humanos e dos Direitos Fundamentais são frutos de uma evolução histórica, uma vez que suas existências estavam resguardadas pelo Jusnaturalismo. Essa corrente - influenciada pela religião e filosofia do mundo antigo - condicionava a existência dos direitos inalienáveis e imutáveis aos indivíduos pelos simples fatos deles existirem. Tal linha de pensamento teve seu apogeu entre os séculos XVI e XVIII a partir dos teóricos contratualistas e iluministas de modo que o Direito Natural passou a ter uma racionalização, desmembrando-se, assim, do pensamento divino e aproximando-se da racionalidade humana (SARLET, 2009, p. 36-38).

Posteriormente, as revoltas e declarações passaram a marcar, cada vez mais, um surgimento das positivações desses direitos. Assim, em 1776, surge a Declaração de Direitos de Virgínia, marcando o surgimento da era do Direito Positivo e, com isso, influenciando as demais Declarações a seguirem o mesmo caminho. A partir dessas inserções surgem diversos arcabouços legais como a Declaração dos Direitos do Homem e do Cidadão (1789) os quais visam atribuir aos direitos fundamentais uma ótica universal, impedindo desigualdade entre os indivíduos a partir de uma lógica liberal (MEIRELLES; RESENDE, 2015, p. 5-8). É nesse contexto que surgem as dimensões dos direitos fundamentais, sendo classificadas a partir do momento ao qual foram conquistados.

Com isso, há o surgimento dos direitos fundamentais de primeira dimensão, os quais são frutos de um Estado Liberal e, por isso, garantem a liberdade individual, culminando na obrigação de não fazer por parte do Poder Público, o que resulta na denominação de direitos de defesa. Posteriormente, após a crise a qual o liberalismo provoca, há a inserção do modelo de Estado Social em que é baseado na intervenção estatal, sendo chamado de direito de prestação. Por fim, há a introdução dos direitos fundamentais de terceira geração os quais rementem aos direitos na esfera transindividual (MEIRELLES; RESENDE, 2015, p. 4-9).

Diante disso, o direito reprodutivo é introduzido, gradativamente, no Ordenamento Jurídico, estabelecido tanto em documentos internacionais - como já mencionado - quanto no ordenamento brasileiro, sendo definido, basilarmente, no capítulo VII, da Plataforma de Ação do Cairo:

Os direitos reprodutivos abrangem certos direitos humanos já reconhecidos em leis nacionais, em documentos internacionais sobre direitos humanos, em outros documentos consensuais. Esses direitos se ancoram no reconhecimento do direito básico de todo casal e de todo indivíduo de decidir livre e responsavelmente sobre o número, o espaçamento e a oportunidade de ter filhos e de ter a informação e os meios de assim o fazer, e o direito de gozar do mais elevado padrão de saúde sexual e reprodutiva. Inclui também seu direito de tomar decisões sobre a reprodução, livre de discriminação, coerção ou violência (§ 7.3).

É nesse contexto que, em 1979, a Convenção sobre a Eliminação de Todas as Formas de Discriminação contra a Mulher (CEDAW) surge, estabelecendo precedentes para fundações de mais diversas instituições com intuitos semelhantes, a exemplo da Convenção interamericana para prevenir, punir 
e erradicar a violência contra a mulher, o que garante a proteção internacional dos direitos reprodutivos, conforme pontuado em seu artigo $1^{\circ}$ :

[..] A expressão “discriminação contra a mulher" significará toda a distinção, exclusão ou restrição baseada no sexo e que tenha por objeto ou resultado prejudicar ou anular o reconhecimento, gozo ou exercício pela mulher independentemente de seu estado civil com base na igualdade do homem e da mulher, dos direitos humanos e liberdades fundamentais nos campos político, econômico, social, cultural e civil ou em qualquer outro campo.

No que tange ao Direito Pátrio, o direito reprodutivo é inserido não só em leis ordinárias - como a “Lei do Planejamento Familiar”, Lei n 9263/96 e a “Lei Maria da Penha”, n 11.340/06, mas também na Constituição Federal de 1988, a qual define em seu art. 226, §7:

Fundado nos princípios da dignidade da pessoa humana e da paternidade responsável, o planejamento familiar é livre decisão do casal, competindo ao Estado propiciar recursos educacionais e científicos para o exercício desse direito, vedada qualquer forma coercitiva por parte de instituições oficiais ou privadas (sem grifo no original).

Apesar de previsto no art. $6^{\circ}$ da Constituição como "proteção à maternidade", essa concepção não abrange o direito reprodutivo como um todo (ALVES; PEGORER, s.d, p. 11) e assim, não integra o rol do Título II da Carta Magna. Diante disso, é factível a possibilidade de estar dispersos em outras partes do mandamento Constitucional, a exemplo do texto "Da Ordem Social" - como acima citado.

Essa possibilidade de alocação encontra-se positivada no art. $5^{\circ} \S 2^{\circ}$ : "Os direitos e garantias expressos nesta Constituição não excluem outros decorrentes do regime e dos princípios por ela adotados, ou dos tratados internacionais em que a República Federativa do Brasil seja parte" e refere-se aos direitos materialmente fundamentais, isto é, são direitos com status fundamental embora não estejam dispostos no catálogo principal, diferente daqueles denominados formalmente fundamentais. Isso se dá porque estes direitos são frutos de um processo histórico e, assim, são variáveis a fim de garantir o máximo possível de dignidade humana (SARLET, 2009, p. 73-86).

Ademais, é importante destacar que os Direitos Humanos e os Direitos Fundamentais, apesar de possuírem uma relação próxima, são distintos. Isso porque, embora os titulares de ambos sejam os seres humanos - mesmo que representados pelo coletivo - os direitos humanos possuem um conteúdo mais amplo e impreciso do que os direitos fundamentais porque encontram-se positivados em documentos internacionais e não nas Constituições dos Estados, como aqueles, em que possuem destinatários específicos de um ente público (SARLET, 2009, p. 29-32).

Por sua vez, como bem destaca Piovesan (2012), os direitos humanos podem ser divididos em instrumentos de alcances gerais e instrumentos de alcances específicos, o que permite a especificação do sujeito e o fim do tratamento universal para com todos os indivíduos. Em consequência disso, é possível notar uma maior visibilidade a grupos mais vulneráveis e, assim, garantir uma maior eficácia dessa aplicação, uma vez que determinadas violações precisam de reações específicas 
Conforme pontuado suas distinções, pode-se perceber que o direito reprodutivo possui uma dupla esfera, sendo a negativa a necessidade de o Estado não interferir nesse direito e a positiva à urgência deste em praticar atos para sua eficácia. Entretanto, em ambas as dimensões, o Estado possui o dever de promovê-lo, de protegê-lo e de respeitá-lo (PEGORER; ALVES, 2012, p. 7).

Apesar de já estar consagrado nesses ordenamentos jurídicos, as mulheres encontram-se, constantemente, violadas no que diz respeito, também, a esses direitos, tendo em vista que $53 \%$ das mulheres mortas no parto são negras (VEJA SAÚDE, 2020). Desse modo, é perceptível que, embora a luta incessante das feministas tenha surtido efeito para o reconhecimento em dispositivos normativos, não tem sido o suficiente para garantir a proteção dessas pessoas. Isso se dá porque os membros do Poder Legislativo, muitas vezes, elaboram leis apenas para agradar a insatisfação popular, mas, na realidade, o pensamento dos indivíduos que compõem a máquina estatal é ainda condescendente com o patriarcado (KARAM, 2015). Sendo assim, nada adianta elaborar leis ou positivar direitos se não estabelecer políticas públicas para promover sua efetividade.

Diante desse cenário, os movimentos lutam pela proteção desse direito a fim de retirar a ideia da maternidade compulsória imposta às mulheres, destituindo, assim, as concepções patriarcais enraizadas socialmente. Ferreira (2015) afirma que tal dificuldade em promover eficácia a esses direitos se dá devido a sociedade patriarcal, na qual incumbe a mulher o dever de arcar com as consequências da prática sexual, uma vez que enxergam no ser feminino a mentalidade fundamental de procriação.

Nesse contexto, é nítido que o esforço do feminismo em retirar o pensamento da maternidade compulsória não é retirado totalmente de cena. Sendo assim, a mulher é tida como a responsável pela dor e - até mesmo por métodos abusivos - no momento do parto, por exemplo. Ademais, pode-se perceber a acentuação dessa visão no que tange às mulheres negras, uma vez que estas, além de responsáveis pela prática, possuem - segundo o imaginário social - o dever de ser forte e suportar a dor e a anatomia de um quadril largo no qual as classificariam como "parideira por excelência".

Com a letargia da efetividade pela máquina estatal, o neoconstitucionalismo obriga ao Estado a promoção do respeito e da reparação dessas violações. Sendo assim, o ativismo judicial, com a judicialização da saúde, tem buscado promover a reparação de casos de violência obstétrica. Entretanto, não há o reconhecimento de que essa violência é fruto do sexismo e do racismo (NOGUEIRA; SEVERI, 2017, p. 5) e, por não haver uma legislação específica sobre o tema, é enquadrado em outras tipificações como a lesão corporal, ou, até mesmo, não se é reconhecido o crime, devendo ser submetido à Comissão Interamericana de Direitos Humanos, o que causa um transtorno ainda maior para a vítima, visto que a mulher teve lesionada não só a sua saúde e seu direito reprodutivo, mas também a sua autonomia e, assim, a sua dignidade e autodeterminação, fruto de um sistema patriarcal e racista.

\subsection{CRIMINALIZAÇÃO DA VIOLÊNCIA OBSTÉTRICA E AS OPOSIÇ̃̃ES}

A violência obstétrica é objeto de Lei em alguns países como a Argentina e a Venezuela, a qual apresenta um arcabouço legal acerca do conceito dessa violência, das condutas e das sanções. É possível perceber que a Lei Venezuelana (Lei $n^{0} 38688$ ), promulgada em 2007, possui sanções, inclusive, privativas de liberdade, enquanto na Argentina (Lei n² 25992), promulgada em 2004, possui apenas sanções admi- 
nistrativas e no que tange ao resultado após a elaboração destas, não se vê diminuição desses casos na Argentina, tendo em vista que não há políticas públicas (DÍAZ GARCIA; FERNÁNDEZ, 2018, p. 129-132).

Diferente destes países, a violência obstétrica no Código Penal brasileiro não se encontra tipificada, sendo equiparada a outros crimes já inseridos no Código, como a injúria, o constrangimento ilegal, a lesão corporal e a exposição do perigo à vida. Tal ausência de criminalização pode ser explicada pelo pensamento colonial, mas também pelas correntes do Direito Penal, na qual acreditam no absurdo dessa criminalização. A primeira delas é a corrente que defende o expansionismo penal e argumenta contrário a essa criminalização por defender já existir tipificação existente no Código Penal, nada impedido de ser encaixado em crimes como lesão corporal. A segunda corrente é a do abolicionismo penal, na qual acredita que a criminalização da violência obstétrica nada mais é expandir o poder punitivo e dar voz ao direito penal simbólico, legitimando, assim, o direito penal (MENDES, 2017, p. 209).

Nesse sentido, é importante frisar para aqueles contrários a essa tipificação que o crime de violência obstétrica não se limita a apenas um simples constrangimento ou uma simples lesão corporal por motivos genéricos. Não, a violência obstétrica é apenas o reflexo de uma sociedade ainda colonial, já que este não é um momento histórico superado, como assevera Navaz (2008, p. 31-73 apud MENDES, 2015, p. 94), uma vez que esse crime constitui-se na desigualdade, na privação da autonomia da mulher e, consequentemente, a sua redução a um objeto, principalmente no que tange às mulheres negras, o modo como essa desumanização ocorre refere-se ao modo como as mulheres e como, sobretudo, as mulheres negras, são tratadas na sociedade.

Desse modo, equiparar essa conduta com as já existentes sem considerar uma perspectiva garantista e feminista, é perpetuar o preconceito e limitar a violência a só mais uma conduta comum. Assim como aponta Soraia da Rosa Mendes (2017, p. 211), “a ação é matar uma mulher por ser mulher, o 'resultado' é a morte de uma mulher e o 'nexo de causalidade' é um sistema de opressão que não só seletivamente, mas também seleciona aqueles/as que merecem a proteção”.

Diante disso, a tipificação da violência obstétrica, embora pareça uma legitimação ao poder punitivo, na realidade procura reparar àquelas mulheres que foram vítimas de um sistema de saúde com marcas ainda coloniais, utilizando-se de um direito penal mínimo para os direitos fundamentais das mulheres como uma resposta ao débito social que o Estado tem com estas, sobretudo, com as negras (MENDES, 2017, p. 172).

Atualmente, os casos de violência obstétrica vêm sendo - como constatado ao longo dessa pesquisa - ainda mais incidente em mulheres negras, e estas nem mesmo buscam a reparação porque não sabem que é uma violação, como o caso de não permitirem acompanhantes na sala de parto, violando a Lei do Acompanhante (Lei no 11.108/05), em que essa violência tem muito mais incidência em não brancas (PARTO DO PRINCÍPIO, 2012, p. 21).

Nesse sentido, a criminalização dessa conduta é necessária, tendo em vista que a partir dela terá um conceito do que seriam todas as ações nas quais se encaixam no conceito de violência obstétrica, não deixando margem, assim, para abusos de menor potencial, mas que causam, ainda assim, danos para estas mulheres. Entretanto, como já discutido, a tão somente criminalização como uma resposta aos anseios sociais não é o suficiente. É urgente a implementação de políticas públicas as quais visem explicar o que faz parte de uma agressão obstétrica, já que a sociedade é claramente 
desinformada acerca deste assunto, além de um atendimento em que garanta humanização nas práticas obstétricas e que proporcione equidade para as mulheres, pois nada adianta superar o sexismo institucional e ainda perpetuar o racismo presente nos hospitais.

\section{CONSIDERAÇÕES FINAIS}

O objetivo central deste artigo foi, além de dar maior incidência ao debate acerca do racismo institucional na saúde obstétrica, retratar a violação de direitos humanos e fundamentais decorridas desse abuso obstétrico. Diante disso, o presente trabalho também visou demonstrar o dever estatal de criminalizar a violência obstétrica em combinação com o implemento de políticas públicas a fim de dar efetividade à tipificação.

Partiu-se da premissa que o direito reprodutivo está inserido implicitamente no rol de direitos fundamentais e, assim, é legítimo, tendo em vista que a Carta Magna assegura, expressamente, a não taxatividade do Título II. Dessa forma, o direito reprodutivo é decorrente do princípio da dignidade da pessoa humana, do direito ao planejamento familiar, à vida, à saúde, bem como à igualdade e à liberdade.

Desse modo, devido à omissão do Estado frente a recorrência da violência obstétrica, o Poder Judiciário a classifica apenas como uma lesão corporal ou, até mesmo, constrangimento, como fora exposto, sendo que os profissionais os quais violaram essas parturientes nunca são devidamente responsabilizados, tendo em vista que a busca pela reparação não é grande - por assim desconhecer a possibilidade - ou, quando ocorre, é denominada tão somente como passível de danos morais.

Entretanto, é inócuo tratar a violência obstétrica nas mulheres, sobretudo em negras, como somente uma questão de responsabilidade objetiva dos profissionais na esfera cível, pois as violações não são por motivos genéricos, mas sim frutos de uma agressão interseccional, devendo, nesse sentido, tipificar tal conduta.

\section{REFERÊNCIAS}

ALMEIDA, Silvio. Racismo estrutural. São Paulo: Pólen Produção Editorial LTDA, 2019.

PEGORER, Mayara Alice Souza; ALVES, Pedro Gonzaga. O reconhecimento dos direitos sexuais e reprodutivos da mulher como direitos fundamentais frente aos novos paradigmas sociais: reafirmando a democracia. In: XXI Encontro Nacional do CONPEDI, 2012, Uberlândia. Anais do XXI Encontro Nacional do CONPEDI/UFU. Florianópolis: Fundação Boiteux, 2012. Disponível em: http:// www.publicadireito.com.br/artigos/?cod=3dd48ab31d016ffc. Acesso em: 30 mar. 2020.

ÁVILA, Ana Paula Oliveira; MELLO, Karen Cristina Correa. A proteção dos direitos sexuais e reprodutivos na Corte Interamericana de Direitos Humanos e a teoria dos diálogos jurisdicionais.

REVISTA QUAESTIO IURIS, v. 12, n. 2, p. 266-292, 2019. 
BARBOSA, Fabiany Glaura Alencar. A abolição da escravidão e modos de pensar e de representar a experiência passada: Livros didáticos (1865-1918). 2012. Dissertação (Mestrado em História) Programa de Pós-Graduação em História, Universidade de Brasília, Brasília, DF, 2012.

BRASIL. Decreto-Lei 2.848, de 7 de dezembro de 1940. Código Penal. Diário Oficial da União, Rio de Janeiro, 31 dez. 1940.

BRASIL. Constituição (1988). Constituição da República Federativa do Brasil, 1988. Brasília: Senado Federal, Centro Gráfico, 1988.

BRASIL. Lei nº 9263, de 12 de janeiro de 1996. Regula o $§ 7^{\circ}$ do art. 226 da Constituição Federal, que trata do planejamento familiar, estabelece penalidades e dá outras providências. Diário Oficial da União, Brasília, DF, 15 jan.1996. Seção 1.

BRASIL. Ministério da Saúde. Secretaria de Atenção à Saúde. Departamento de Ações Programáticas Estatísticas. Área Técnica de Saúde da Mulher. Direitos sexuais e direitos reprodutivos: uma prioridade do governo. Brasília: Ministério da Saúde, 2005. 26 p.

COSTA, Emília Viotti. Da Monarquia à República: momentos decisivos. 6. ed. São Paulo: Unesp, 1998.

CRENSHAW, Kimberlé. Documento para o encontro de especialistas em aspectos da discriminação racial relativos ao gênero. Revista estudos feministas, v. 10, n. 1, p. 171-188, 2002.

DAVIS, Angela. Mulheres, raça e classe. São Paulo: Boitempo, 2016.

DAMASCO, Mariana Santos; MAIO, Marcos Chor; MONTEIRO, Simone. Feminismo negro: raça, identidade e saúde reprodutiva no Brasil (1975-1993). Revista Estudos Feministas, v. 20, n. 1, p. 133-151, 2012.

DE RESENDE, Augusto César Leite; DE MEIRELLES, Jussara Maria Leal. A proteção do direito fundamental à reprodução assistida no Brasil. Derecho y Cambio Social, v. 12, n. 39, p. 4, 2015.

DÍAZ GARCÍA, Luis Iván; FERNÁNDEZ, Yasna. Situación legislativa de la Violencia obstétrica en América latina: el caso de Venezuela, Argentina, México y Chile. Revista de derecho (Valparaíso), n. 51, p. 123-143, 2018.

DINIZ, Carmen Simone Grilo; CHACHAM, Alessandra S. O "corte por cima” e o "corte por baixo": o abuso de cesáreas e episiotomias em São Paulo. Questões de saúde reprodutiva, v. 1, n. 1, p. 80-91, 2006. DINIZ, Simone Grilo. Gênero, saúde materna e o paradoxo perinatal. Journal of Human Growth and Development, v. 19, n. 2, p. 313-326, 2009. 
FERREIRA, Kauara Rodrigues Dias. Racismo e sexismo em instituições de saúde do DF: pré-natal, parto e pós-parto de mulheres negras. 2015. Dissertação (Mestrado em Sociologia) - Programa de Pós-Graduação em Sociologia, Universidade de Brasília, Brasília, DF, 2015.

FREYRE, Gilberto. Casa-grande \& senzala. 48. ed. São Paulo: Global, 2003.

HOOKS, Bell. E eu não sou eu uma mulher? Mulheres negras e feminismo. Plataforma Gueto, 2014.

HOOKS, Bell. 0 feminismo é para todo mundo: políticas arrebatadoras. Rio de Janeiro: Rosa dos Tempos, 2018.

LÓPEZ, Laura Cecilia. O conceito de racismo institucional: aplicações no campo da saúde. Interface-Comunicação, Saúde, Educação, v. 16, n. 40, p. 121-134, 2012.

MARQUES, César Rogério. 0 papel do direito no desenvolvimento econômico e sua relação com a economia política. Natal: Fides, 2017.

MENDES, Soraia da Rosa. Criminologia feminista: novos paradigmas. 2. ed. São Paulo: Saraiva, 2017.

BRASIL. Ministério da Saúde. Secretaria de Gestão Estratégica e Participativa. Painel de indicadores do SUS, v. 7, n. 10. Brasília: Ministério da Saúde. 2017.

NOGUEIRA, Beatriz Carvalho; SEVERI, Fabiana Cristina. O tratamento jurisprudencial da violência obstétrica nos tribunais de justiça da região sudeste. Seminário Internacional Fazendo Gênero 11 \& 13th Women's Worlds Congress. Anais [...], Florianópolis, 2017.

PARTO, DO PRINCÍPIO. Dossiê Violência Obstétrica “Parirás com dor”. CPMI da Violência Contra as Mulheres, 2012.

PASSOS, Rachel Gouveia. Mulheres negras, sofrimento e cuidado colonial. Revista Em Pauta: teoria social e realidade contemporânea, v. 18, n. 45, 2020.

PALHARINI, Luciana Aparecida. Autonomia para quem? 0 discurso médico hegemônico sobre a violência obstétrica no Brasil. Campinas, n. 49, e174907, 2017. Disponível em http://www.scielo.br/scielo. php?script=sci_arttext\&pid=S010483332017000100307\&lng=en\&nrm=iso. Acesso em: 23 ago. 2020.

PATRIOTA, Tania. Relatório da conferência internacional sobre população e desenvolvimentoplataforma de Cairo. 1994. Disponível: http://www. spm. gov. br/Articulacao/articulacaointernacional/relatorio-cairo. pdf. Acesso em: 13 jul. 2020. 
RIBEIRO, Djamila. Quem tem medo do feminismo negro? São Paulo: Editora Companhia das Letras, 2018.

RIBEIRO, Djamila. Lugar de fala. São Paulo: Pólen Produção Editorial LTDA, 2019.

SANTOS, Gyme Gessyka Pereira; SALES, Sandra Regina. A mulher negra brasileira, miscigenação e o estupro colonial: o mito da democracia racial e o reforço de estereótipos racistas e sexistas.

Caderno Espaço Feminino, v. 31, n. 1, 2018.

SCHWARCZ, Lilia Moritz; DOS SANTOS GOMES, Flávio (ed.). Dicionário da escravidão e liberdade: 50 textos críticos. São Paulo: Editora Companhia das Letras, 2018.

STURZA, Janaína Machado; NIELSSON, Joice Graciele; ANDRADE, Estela Parussolo de. Violência obstétrica: uma negação aos direitos humanos e a saúde sexual e reprodutica da mulher. Revista Juris Poiesis, Rio de Janeiro, v. 23, n. 32, p. 389-407, 2020. 
1 Doutor em Direito pela Pontifícia Universidade Católica do Rio Grande do Sul - PUCRS. Mestre em Direito pela Pontifícia Universidade Católica do Paraná - PUCPR.

Especialista em Direito Público pela Universidade Sul de Santa Catarina - UNISUL. Professor de Direitos Humanos e Fundamentais da Universidade Tiradentes - UNIT. Promotor de Justiça em Sergipe.

2 Acadêmica de Direito na Universidade Tiradentes - UNIT.

\section{(@) (1) (-)}

Este artigo é licenciado na modalidade acesso abertosob a Atribuição-Compartilhalgual CC BY-SA

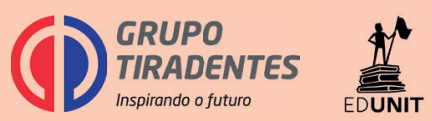

